\title{
LA PERSISTENCIA DEL CREER O LA EMERGENCIA DE LO SAGRADO EN LAS COMUNIDADES NEGRAS DEL VALLE INTERANDINO DEL PATÍA, COLOMBIA*
}

\author{
THE PERSISTENCE OF BELIEVING OR THE EMERGENCY OF THE SACRED \\ IN THE BLACK COMMUNITIES OF THE INTERANDINO VALLEY OF PATÍA, \\ COLOMBIA
}

\author{
José Rafael Rosero Morales**
}

\begin{abstract}
El presente artículo centra su atención en los argumentos que sustentan, desde la perspectiva teórica como contextual, la configuración de aquello que hemos dado en llamar la emergencia o la construcción de un nuevo horizonte religioso, en el marco de las comunidades negras del valle interandino del río Patía (Cauca, Colombia). El artículo se desarrolla en cuatro bloques de exposición. El primero expone algunos planteamientos en torno a las dinámicas del creer en contextos religiosos plurales contemporáneos y sus implicaciones, en términos de la persistencia o del vaciamiento del creer, en el marco de comunidades bajo el inevitable influjo de discursos y prácticas seculares. El segundo da cuenta de aquellos rasgos que particularizan la emergencia de lo sagrado desde un nuevo horizonte religioso. El tercero y cuarto ofrecen un análisis derivado de la confrontación crítica de los dualismos monoculturales prescritos por Occidente para la regulación de lo sagrado, que permitan poner en evidencia un horizonte que asume y se disputa por hacer manifiesto lo sagrado, desde otro patrón epistémico, sociocultural y religioso.
\end{abstract}

Palabras clave: Creencia, pluralismo religioso, sagrado y profano, valle del Patía, colonialidad religiosa, marginal.

This article focuses on the arguments that support, from a theoretical and contextual perspective, the configuration of what we have called the emergence or construction of a new religious horizon, within the framework of the black communities of the Inter-Andean Valley of Patía river (Cauca, Colombia). The article is divided into four blocks of exposure. The first presents some approaches to the dynamics of contemporary plural believe in religious contexts and its implications, in terms of persistence or emptying believe, in the context of communities under the inevitable influence of secular discourses and practices. The second realizes those features that particularize the emergence of the sacred from a new religious horizon. The third and fourth offer a derivative of the critical confrontation of the West's monocultural dualisms for the regulation of the sacred, which allows highlighting a horizon that assumes and is disputed by making manifest the sacred, from another epistemic pattern analysis, socio-cultural and religious.

Key words: Belief, religious, sacred and profane pluralism, Valle del Patía, religious colonialism, marginal.

\section{Introducción}

El pluralismo religioso es un hecho en Colombia y demás países de América Latina. Podría afirmarse que hoy asistimos a un escenario, cuya transformación en curso da cuenta del modo cómo se ha venido produciendo modificaciones sustantivas y permanentes en la cartografía religiosa que definía a las sociedades latinoamericanas y específicamente la colombiana, como mayoritaria y hegemónicamente católica. En otras palabras, América Latina ya no es católica ${ }^{1}$, diría Cristian Parker (2005). Hecho que invita a reconocer la complejidad y el dinamismo que adquieren las expresiones religiosas en contextos globales, al igual que sus implicaciones, en contextos locales tradicionales e institucionales, los que están experimentando importantes transformaciones en el plano de las creencias y las prácticas de religiosidad.

De hecho, para las comunidades negras del valle interandino del río Patía, al sur del departamento del Cauca, Colombia -de las que nos ocupamos en este artículo-, este escenario religioso plural contemporáneo, caracterizado por la creciente diversificación religiosa ${ }^{2}$, constituye una realidad de la que no es posible escapar. Sin embargo, uno de los aspectos que interesa destacar en este estudio es cómo en el marco de esta diversidad religiosa, los universos simbólicos de dichas comunidades le confieren mayor significado a la recuperación y

\footnotetext{
* Este artículo forma parte de los resultados del proyecto de investigación: "Cimarronaje religioso, recuperación cultural de la memoria colectiva y prácticas de re-existencia". Grupo de Investigación Cultura y Política, Universidad del Cauca.

** Universidad del Cauca. Departamento de Filosofía, Popayán, Colombia. Correo electrónico: jrosero@ unicauca.edu.co
} 
revitalización de prácticas religiosas marginales ${ }^{3}$, en donde la religiosidad y la espiritualidad converge con la historia local ${ }^{4}$, la memoria colectiva e inevitablemente con elementos dispersos del catolicismo, dando lugar así a una realidad socioculturalmente construida, cuya legitimidad no deviene de lo sagrado institucionalmente impuesto sino de lo sagrado sentipensado ${ }^{5}$ por las comunidades.

Estos elementos, como puntos de referencia, nos permitirá avanzar en las distinciones analíticas que contribuirán en la comprensión del sentido que adquieren las complejas dimensiones que los sujetos tejen entre lo religioso y lo sagrado.

\section{Pluralismo religioso y recomposición ${ }^{6}$ del creer}

Los hombres y mujeres de hoy no creen (o dudan) más o menos que hace cien o cincuenta años. Creen (y dudan) de manera diferente

(Mallimaci 2008:16).

Con el advenimiento de la modernidad, considerada hija de la Ilustración y por tanto de la secularización, se llegó a pensar que la religión dejaría de ejercer su influjo en las estructuras de la organización social y que, por tanto, aquellos fenómenos que antes recibían una interpretación directamente religiosa serían explicados y comprendidos a la luz de la subjetividad, como principio orientador de los núcleos de la organización social moderna: capitalismo, industrialización y democracia. "Hubo tiempos en que Dios habitaba con normalidad en la cultura occidental. Hoy Dios es un ausente" -dice Mardones-y agrega: "Y lo más llamativo es que no se nota. No se le echa en falta a este huésped, que era lo necesario y fundamental para la vida de otros hombres en otras épocas" (Mardones 1999a: 99).

Por tanto, la emancipación del ser humano de la tutela espiritual y la conversión de las relaciones sociales como consecuencia de la ruptura con la organización social tradicional, conllevaría al ser humano a la constitución de su propia normatividad; el ser humano, sujeto a este proceso de secularización podría ser pensado sin lo sagrado, en tanto el predominio de la racionalidad instrumental tendería a evacuar los cuestionamientos respecto de las causas últimas, la profundidad y el misterio. Se trata, entonces, de conceptualizaciones cuyos relatos (modernos) y metarrelatos (posmodernidad) de carácter difusionista, pregonan que la profundidad, el misterio, lo sagrado, los mitos, los ritos; la no identificación de la política con el Estado o el Partido; de lo político con la esfera de lo público, ya no constituyen expresiones culturales de las formas de relación social, como consecuencia de la crisis y ruptura paradigmática entre cristianismo y modernidad. Lo anterior, por cuanto la emergencia de ese "nuevo mundo" es un obstáculo para ser asimilado por el viejo paradigma de la cristiandad y la política, el que quedó desplazado por un nuevo paradigma cultural que, para muchos, es una de las principales fuentes del ateísmo y de las refundaciones de lo político. Quizá, la mejor expresión del carácter difusionista de estos relatos es la presunción de que la abundancia de la indiferencia agnóstica en los seres humanos y las rupturas con la estructura social tradicional, es consecuencia del despliegue de la secularización, de la idea de emancipación y del supuesto relativo influjo de la religiosidad en las estructuras de la organización social.

Todo parece indicar que aquellas hipótesis acerca de la secularización que pregonan los metarrelatos y que suponían la decadencia y desaparición de la religión (Comte, Feurbach), la mundanización de lo religioso (funcionalismo-aggiornamento), la separación y la independencia entre la sociedad y la religión (Kant-Weber) y, la desacralización total del mundo (positivismo) (Arboleda 2005: 94), distan de ser reales hoy. Pues, las sociedades latinoamericanas y específicamente la sociedad colombiana es la más clara expresión de que la eliminación de la religión y la secularización ${ }^{7}$ como el final de la misma, en tanto hipótesis de la modernidad y posmodernidad, han sido refutadas.

Por ello, desde nuestra perspectiva, lo que no es claro del discurso de la modernidad y postmodernidad (modernidad aplazada o desencanto del desencanto) es si lo que se cuestiona es la fe, los imaginarios y las prácticas sociales o la cultura en la que estas manifestaciones se encuentran involucradas; porque una cosa es producir cambios en la interpretación teológica y política de la experiencia cristiana a partir de nuevos paradigmas y otra muy distinta es producirlos desde la experiencia misma; es decir, desde las constelaciones de creencias ${ }^{8}$, experiencias y valores que adquieren y representan significados para la existencia humana. Por eso afirma Hervieu-Léger:

La modernidad ha deconstruido los sistemas tradicionales del creer: sin embargo, no ha 
vaciado el creer. Este se expresa de manera individualizada, subjetiva, dispersa, y se resuelve a través de las múltiples combinaciones y disposiciones de significados que los individuos elaboran de manera cada vez más independiente del control de las instituciones del creer (y, en particular, de las instituciones religiosas) (Hervieu-Léger 2005: 126).

Este planteamiento remite a considerar las creencias y las prácticas religiosas con sus diferentes mediaciones simbólicas como partes constitutivas del entramado social, en las que convergen expresiones asociadas a la memoria colectiva, las tradiciones, la recomposición de identidades, y la diversificación de las formas del creer, tanto en el plano individual como en el colectivo. Un aspecto distintivo de estas creencias y prácticas, es que se inscriben en una concepción de religiosidad que en la actualidad "[...] se encuentra enmarcada profundamente en las matrices culturales de los sectores populares y en los procesos de recomposición de creencias y prácticas que los mismos llevan a cabo cotidianamente, sin estar sujeta a las instituciones religiosas reconocidas y consolidadas" (Ameigeiras 2008: 9).

Lo anterior supone una particular manera de entender, denominar y de relacionarse con lo sagrado. Así como también, unos sujetos en cuyos imaginarios sociales, lo religioso se manifiesta de diversas formas: en la intimidad de la oración, en la multiconfesionalidad, en la visita de templos y capillas, la concurrencia a santuarios, las romerías y peregrinaciones, las alumbranzas a santos o imágenes de preferencia, la construcción de altares, la organización y participación en fiestas a los santos patronos, los rituales para la vida y la muerte, la asistencia a salones del reino, la participación en ceremonias y cultos, entre muchos otros. Por tanto, la supervivencia de estas prácticas religiosas y formas del creer, su empeño por conservar su lugar e importancia, aún en períodos de crisis, al igual que la emergencia de visiones alternativas de lo religioso ${ }^{9}$, son una contundente demostración de aquello que hemos dado en llamar la persistencia del creer. Así lo confirma Nikos Kokosalakis, cuando plantea que:

[...] el hombre de los tiempos modernos es tan religioso como lo era en el pasado, aunque el tipo de trascendencia que le preocupa difiere bastante de los periodos anteriores de la historia. Se puede afirmar que si lo sobrenatural es solo una modalidad de reconstrucción de la trascendencia, su decadencia en la sociedad moderna revela el decaimiento de algunas formas históricas y culturales de la religión, pero no significa la decadencia de la religión en sí (Kokosalakis en Mallimaci 1993: 117).

En esta dirección, si se aceptase una crisis desde el punto de vista religioso en el contexto colombiano, se podría plantear que esta no vendría de procesos o de formas "duras" de secularización, sino del pluralismo religioso moderno (Arboleda 2005: 98), que conduce a la relativización total de los sistemas de valores, esquemas de interpretación y procesos de elección personal e individual, donde cada cual absorbe su porción simbólica y la combina con otras porciones provenientes de otros caudales de sentido, dando forma así a otros mundos de vida, de sentido, para dar seguridad a las existencias. A este respecto, conviene señalar, sin lugar a dudas, que el pluralismo religioso es un hecho en Colombia y demás países de América Latina y, como tal, ha modificado sustantivamente el mapa religioso que definía las sociedades latinoamericanas y específicamente la colombiana, como mayoritaria y hegemónicamente católica ${ }^{10}$. Fenómeno de cambio cultural profundamente significativo que algunos teóricos de las ciencias sociales han optado por llamar "mutación religiosa" (Bastián 2003), "fragmentación del campo religioso católico" (Parker 1996, 2005), "religión en movimiento" (Hervieu-Léger 2005), "retorno de lo religioso" (Mardones 1999b), "revival religioso" (Roldán 1999), de "cambio religioso y transformación cultural" (Marzal 2002) o, "Lugar teológico auténtico de transmisión y reafirmación de la tradición cristiana", y "criterio de discernimiento para la crisis actual" (Aguirre 2020).

De esta manera, el pluralismo religioso sería la expresión de la tensión e intensificación de las identidades y las diferencias religiosas, sin que ello implique socavar, remover o descentrar los dispositivos de control epistémico, social, cultural, teológico, económico y político, de los sujetos de la enunciación religiosa colonial. En otras palabras, asumir dicha perspectiva de análisis no es otra cosa que producir un desplazamiento dentro del marco particular de las lógicas modernistas. Por ello y 
como bien lo ha planteado Hervieu Léger, "la secularización no es la desaparición de la religión confrontada con la racionalidad: es el proceso de reorganización permanente del trabajo de la religión en una sociedad estructuralmente impotente para satisfacer las esperanzas que es preciso suscitar para que exista como tal" (1987: 227).

\section{La emergencia de un nuevo horizonte religioso}

En las comunidades negras del valle del Patía se reconoce la tradición, el significado y el valor de manifestaciones sujetas al calendario festivo católico como la Semana Santa, la Navidad y, en particular, las fiestas a los santos patrones. Es el caso de la virgen del Tránsito, la virgen del Carmen, la virgen de las Mercedes, San Miguel Arcángel y San Martín de Porres, los que son asumidos como referentes históricos de identidad religiosa y modeladores de su accionar comunitario. Sin embargo, recordemos con Paulo Freire que "las formas de ser y de comportarse de los oprimidos reflejan en diversos momentos la estructura de la dominación" (Freire 2002: 57). De ahí que la participación de los patianos y patianas en dichas tradiciones no supone necesariamente la obliteración del cuestionamiento y toma de posición frente a la legitimidad histórica de la Iglesia Católica en materia de regulación y control de la dinámica sociocultural y religiosa.

Contrario a ello, podría decirse que su incesante búsqueda de la autolegitimación del mundo negro, mediante el reencuentro con lo ancestral, al igual que el reconocimiento y valoración del papel que desempeñó entre las comunidades negras la estrategia defensiva puesta en marcha por los esclavos y sus descendientes, consistente en términos generales en la adopción de ciertas formas de protección ante la actitud beligerante de la Iglesia Católica y la sociedad colonial, se niegan a dejar de existir y de hacerse manifiestos. En esta dirección, José Fernando Serrano nos recuerda que "La permanencia del celo oficial hacia las formas de religiosidad negra permite pensar tanto en la constancia del ejercicio de la negación como en la permanencia del resistir y la búsqueda de prolongación a lo largo de la historia de sus mundos espirituales" (Serrano 1998). Esto permite comprender, de alguna manera, por qué las modalidades rituales de celebración guardan distancia, tanto en su concepción como en su realización, del catolicismo. Quizá por ello, "los rituales religiosos populares afrodescendientes, a pesar de tener tantos elementos como contenidos casi estrictamente católicos -por la colonización europea-, son, en sí mismos, una forma de resistencia que nace históricamente por la imposibilidad de las y los negros de asistir a los ritos católicos" (Alves y Pérez 2016: 83). En este orden de ideas, la religiosidad y espiritualidad no supuso aludir a un ámbito de creencias individuales aisladas, sino más bien a una visión de mundo que determina la manera cómo, en la dimensión espacio-temporal, el mundo se configura ante dichas comunidades. Es decir, "una visión estructurada en la cual los miembros de una comunidad combinan de manera coherente sus nociones sobre el medio ambiente en que viven, y sobre el cosmos en que sitúan la vida del hombre" (Broda 2001 citado por Gómez 2007: 163).

Lo que se advierte en estas comunidades es una suerte de pensamiento-otro (heterológico) ${ }^{11}$, mediante este, comprenden sus existencias vinculando al ser humano con el mundo por medio de una relación dialógica fluida que privilegia sus experiencias religiosas por sobre las explicaciones racionales. Pensamiento otro (heterológico) que, siguiendo a Brower (2007), puede ser entendido como un conjunto de procedimientos interpretativos y comprensivos del mundo en sus dimensiones cultural y natural, puestos en acción al interior de una cultura determinada. Procedimientos que para el análisis y la comprensión del campo religioso y ritual, se diferencian y distancian de la lógica logocéntrica desarrollada en Occidente, al mismo tiempo que la ponen en cuestión.

Precisamente, las cualidades heterológicas, si se quiere "seminales" para expresarlo en términos de Rodolfo Kusch"12(1973) o, "hemidernas" en la dirección de Cristian Parker (1996), en el marco de culturas religiosas afro y sus múltiples expresiones simbólicas, resultan, en el mayor de los casos, incomprensibles desde las categorías heredadas de la cultura occidental. Lo que expresa esta afirmación distintiva es que los saberes, las cosmovisiones y las prácticas religiosas, particularmente de las comunidades negras, difícilmente se dejan comprender y mucho menos someter e inscribir en el marco de las categorías y narrativas excluyentes de la lógica occidental, propio de los enfoques y campos disciplinares que se ocupan del hecho religioso, principalmente provenientes de la sociología, la antropología, la fenomenología y la teología. Imposibilidad que reside, fundamentalmente, en la tendencia de estas narrativas a producir y 
reproducir dualismos que polarizan los horizontes religiosos y, por consiguiente, a aceptar o rechazar las otredades religiosas, siempre en relación al patrón civilizatorio cristiano.

Este planteamiento nos remite a no perder de vista $y$, en consecuencia, a reafirmar que uno de los elementos estructurales que garantizó la reproducción de las relaciones de dominación en el proceso de conquista y colonización de América, fue el dogma de Occidente; es decir, el sistema religioso del cristianismo ${ }^{13}$, particularmente aquella versión que adopta el catolicismo como religión y que se organiza y despliega como Iglesia Católica. Esta religión [la católica] se atribuyó el derecho de existir como la única religión válida y verdadera, materializando así, la literalidad de su significado primigenio en griego y latín: ${ }^{14}$ de ser "universal y que lo comprende todo". Patrón de poder que guiaría toda su actividad misionera y en consonancia a sus principios y preceptos, las expresiones religiosas de las poblaciones negras e indígenas, por su carácter "herético" y "supersticioso", debían ser reemplazadas por la "verdadera religión". De esta manera, lo proveniente de dichos universos religiosos sería catalogado como irreconciliable con la doctrina cristiana y transgresión del orden colonial.

La implementación de este proceso se hizo posible, entre otros factores, sustentado en construcciones ideológicas asociadas a la clasificación social, la racialización y la idea de pureza. "Ser clasificado como mestizo o mulato, como español o indio, implicaba una diferencia en la vida, porque la clasificación determinaba los derechos y obligaciones en la sociedad colonial" (Rappaport 2015: 15). El principal propósito era establecer una diferenciación clara y precisa, entre lo que corresponde al ámbito de lo puro, verdadero y auténtico cristianismo, y lo que se sitúa en el ámbito de lo confuso, lo contaminado, lo falso o poco ortodoxo, en materia religiosa y moralidad social. Lo anterior, sobre la base de que para la lógica colonial, la diferencia religiosa podría llegar a ser considerada y hasta cierto punto aceptada, mas no así la mezcla o el entreveramiento religioso. A este respecto, un elemento, entre otros, que permite ilustrar lo anterior, se refleja en la mayoría de sus narrativas. En estas, la apelación a epítetos para designar e identificar aquellas prácticas religiosas consideradas como impuras, iban desde descalificar las mentalidades de quienes experimentan dichas prácticas religiosas como supersticiosas, heréticas, infernales y repugnantes, hasta otorgarle, incluso, color a las mismas; es decir, el color asignado a la superstición era negro, oscuro o pálido.

En esta consideración, no se puede pasar por alto las consecuencias que este dualismo origina, en términos de las políticas de dominación y control respecto de lo sagrado y lo profano. Así como tampoco, que la autenticidad e inautenticidad, o la pureza e impureza, atribuibles a las formas religiosas, son relativas a las cosmovisiones, las asimetrías de poder y los contextos donde se sitúen los sujetos. Desconocer u omitir dichas consecuencias es pretender pensar y creer que una forma religiosa se superpone sobre otra de manera perfecta y absoluta; es decir, sin que dicho proceso suponga tensión y conflicto, no produzca fisuras y pliegues, no deje residuos y sedimentos perdurables de la forma religiosa que se resiste, somete o coloniza, así como también no dé lugar, por parte de los sujetos, a la creación de identidades religiosas propias.

\section{Lo canónico, lo marginal y colonialidad del ser}

Identificar lo institucional con organizaciones religiosas oficiales como referente único del mundo religioso que, para nuestro contexto sociocultural es la Iglesia católica, resulta complejo y problemático. Lo anterior, si se tiene en cuenta que la religiosidad y espiritualidad en las comunidades descritas, no se deja comprender a la luz de lo institucional, en tanto las mismas -como expresión simbólica del mundo religioso patiano- "hace referencia al conjunto de creencias y prácticas religiosas de las poblaciones que no están directamente dominadas ni se ajustan estrictamente a las normas dictadas por las instituciones religiosas oficiales" (Zamora 1989: 530). Más aún, en estas comunidades de cultura, lo religioso se constituye como campo ideológico y simbólicamente autónomo y extraño a la normatividad y directriz eclesiástica oficial.

Lo anterior no implica el desconocimiento de la presencia de una religión organizada eclesiástica con capacidad de ejercer hegemónicamente su poder religioso; sin embargo, estas comunidades no encuentran argumentos razonables para que su conexión con lo trascendental se realice distante o por fuera de su contexto social y ambiental más próximo, y mucho menos mediado por imágenes, 
iconos o símbolos que no reflejen sus universos religiosos. Dicho en pocas palabras: se cree en lo sagrado, pero no necesariamente en lo que la Iglesia ofrece. De ahí sus reservas frente a considerar a la Iglesia como un espacio que represente verdaderamente la comunicación con lo sagrado. Esta capacidad para transformar aquellos elementos y escenarios que en principio corresponden al ámbito de lo profano en ámbitos sagrados, con la finalidad de fortalecer los vínculos de lo humano con lo divino y, en consecuencia, no otorgar plena legitimidad a espacios que históricamente han sido instaurados y reconocidos como sagrados desde la oficialidad religiosa, connota de por sí un particular rasgo de cimarronaje religioso ${ }^{15}$. Quizá, ello también esté relacionado con la tensión histórica generada por el conflicto -aún no resuelto- entre estas comunidades y la Iglesia, en términos de la propiedad territorial donde se asienta el pueblo de Patía. Hecho que activa y actualiza la memoria de los patianos, al punto tal, que en el marco de sus imaginarios no se le exige veracidad histórica al conflicto, sino veracidad social. Podría afirmase, entonces, que la manera cómo estas comunidades encaran la religiosidad y espiritualidad,

[...] es su profunda creencia en lo que la experiencia, la cotidianidad y la sociedad ha sacralizado con sus propias historias. Es decir, las formas como estas comunidades perciben el mundo y las relaciones que establecen al interior de ese mundo, determinan en gran medida cómo dichas comunidades perciben la presencia divina. En este sentido, $[\ldots]$ lo sagrado se asume como una reinvención histórica, cuya principal cualidad es la de ser un espacio en permanente disputa simbólica que expresa relaciones de poder y de resistencia (Rosero 2008: 64).

Se trata entonces de una relación de "oposición, dependencia o yuxtaposición con algo que se entiende es la religión oficial, un sistema teológico que se da en llamar el catolicismo y del que se acepta que es la religión, sin calificativos" (Delgado 1993). El mismo Manuel Delgado señala que una de las tendencias, y por cierto más divulgadas, parte de la premisa de que solo existe la religión católica y que las prácticas piadosas llamadas marginales, populares o rurales, son la manera que tiene esta de darse entre los lugares "bajos" del sistema de estratificación social, incapaces de acceder a la sofisticación del discurso teológico aceptado (Delgado 1993).

Desde esta perspectiva, hablar de religiosidades marginales, fronterizas o disruptivas, como las de las poblaciones negras del Patía, remite a considerar las mismas como un déficit de modernidad. Sin embargo, creemos a nuestro juicio que, más allá del "déficit" de modernidad que supuestamente le atribuyen las narrativas occidentales a las experiencias religiosas llamadas marginales o disruptivas, estamos -para expresarnos en términos de Mignolo (2003)-frente su cara oculta y más oscura, la colonialidad; cuyo modus operandi es la negación y exclusión de lo no europeo como criterio civilizador, sustentado en la premisa de las diferencias culturales como estrategia de encubrimiento de lugares, historias, memorias, cosmovisiones y experiencias existenciales, de quienes han sido objeto de inferiorización e injusticias por parte de quienes agencian el proyecto moderno civilizatorio. De ahí que la instalación, constitución y subsistencia de la colonialidad sea exigida y necesitada por la modernidad en tanto constitutiva de la misma, pues "sin colonialidad no hay modernidad" (Mignolo, 2003). Planteamiento que para el caso que nos ocupa, sería lo propio de la colonialidad religiosa en el contexto moderno, en tanto despliegue ideológico invisible de la colonialidad del ser ${ }^{16}$ (Maldonado-Torres 2007).

Referente al tema, el filósofo Nelson MaldonadoTorres considera que en la configuración del concepto colonialidad del ser, su abordaje conceptual debe partir de las alteridades opacadas; es decir, de los sujetos que han sido expulsados de la historia, los negados y ocultados por las narrativas hegemónicas, cuyas prerrogativas van a constituir el núcleo de la historicidad fanoniana ${ }^{17}$, como dirían De Oto y Quintana (2010).

En este sentido, la colonialidad del ser hace referencia a los efectos de negación, inferiorización y deshumanización, experimentados por los individuos bajo condiciones de subalternización colonial, que para nuestro caso serían aquellos cuyas experiencias y horizonte religioso "no están ahî", no se inscriben o escapan a la colonialidad religiosa. La relevancia de este concepto reside en que permite develar en su compleja dimensión el poder, la mirada colonial y la agencia ideológica del monoteísmo religioso cristiano, sobre todas aquellas expresiones y manifestaciones religiosas al considerarlas como paganas, 
impuras e inferiores y, a quienes las practican, como indignos e impíos. Raúl Fornet nos recuerda en esta dirección que en América "No hubo [...] diálogo de religiones sino 'colonización de almas', con la consiguiente degradación o, peor aún, demonización de los sistemas religiosos autóctonos" (Fornet 2007: 21). Se trata, entonces, de una postura abiertamente antagónica frente a la diversidad de universos religiosos, que sobre la base de autoafirmarse como tradición religiosa superior y verdadera, al igual que como religión con legítima consciencia teológica, se atribuye, de una parte, la condición y capacidad de censurar y condenar las otredades religiosas y, por otra, la potestad para instalar al represor en los sujetos e imponer la razón colonial en las subjetividades y los cuerpos.

\section{Más allá de lo sagrado y profano}

La dicotomía sagrado-profano ${ }^{18}$, en tanto categorías para el análisis e interpretación del fenómeno religioso, no deja se de ser sugerente. Sin embargo, se torna problemático por cuanto asume lo sagrado como fundamento sustantivo, prescriptivo y normativo de un cuerpo de doctrina que se asume como hegemónico, oficial y dominante que, para nuestro caso, es la religión católica. Por tanto, todo aquello orientado a transgredir o alterar la identidad y cohesión social que prescribe lo sagrado católico, tiende a ser reducido por el poder simbólico. En otras palabras, la dicotomía sagrado-profano, cuya conceptualización encierra una determinada visión acerca de lo social, la naturaleza y de los sujetos, niega la posibilidad de acceder a la subsistencia de lo sagrado en el marco de otros contextos socioculturales ${ }^{19}$.

En efecto, la tensión simbólica que se produce en contextos y comunidades como las que nos ocupa, implica no solo las formas cómo las mismas asumen la naturaleza y lo sagrado, sino que también determina las formas de representación de aquello que se considera como sagrado y profano. Por ello, más allá del horizonte de análisis propuesto por las narrativas occidentales, consideramos que lo sagrado puede ser asumido como todo aquello que permite establecer relaciones más cálidas y sentidas entre las divinidades, los seres humanos y la naturaleza. Donde las formas que particularizan el modo de asumir la vida y la muerte, el cuerpo y la enfermedad, lo lúdico y la risa, la música y el baile, los cantos y los rezos, las ceremonias y los ritos, la naturaleza y el territorio, y demás manifestaciones que la mirada colonial considera profanas, no son rechazados; en tanto lo que precisamente nutre y da contenido a la experiencia religiosa es su contacto con todo aquello, lo cotidiano. Donde lo sagrado refiere una actitud y un espacio privilegiado donde los seres humanos logran cuestionar quiénes son, al tiempo que es el devenir singular de las comunidades lo que define, recrea y resignifica las orillas que -de existir- hacen evidente el límite con lo profano. Por ello, como bien lo advierte Parker, esta forma de asumir el mundo religioso le plantea

\section{[...] un serio desafío a la definición so- cialmente dominante de lo sagrado -que sutilmente, por lo demás, está siendo impuesta no por una sociedad supraindi- vidual, sino por los grupos e instituciones que detentan el monopolio de lo sagrado (Parker 1995:138).}

Por consiguiente, y a partir de todo aquello que hemos abordado anteriormente, se podría afirmar que en las comunidades negras del valle interandino del río Patía, lo que se observa es la emergencia y subsistencia de otra lógica u horizonte para la comprensión de su campo religioso y ritual. Se trata de una lógica que hace evidente cómo sus prácticas religiosas no se reducen ni agotan en lo formal de la institucionalidad religiosa (doctrina, liturgia y culto), sino que trascienden en tanto prácticas derivadas de experiencias existenciales [espirituales] que emergen, se adaptan y responden a las condiciones socioculturales y del medio, en una triple relación que implica la relación con la naturaleza, con los seres humanos y con lo trascendente, y la forma de simbolizar estas relaciones, en contextos históricos específicos (Minda 1996: 263). Triple relación que, vista desde la perspectiva de Raimon Panikkar ${ }^{20}$, permite mostrar el elemento empírico (o físico), el factor noético (o psíquico) y el ingrediente metafísico (o espiritual) de la realidad (Cfr. Panikkar 1999:94), cuyo punto de partida sería aquella intuición fundamental de los seres humanos, denominada por el autor como cosmoteándrica; es decir, según esta, "El hombre únicamente es hombre cuando tiene el cielo sobre él, la Tierra debajo y sus semejantes a su lado" (Panikkar 1999:97).

Esta forma de encarar lo religioso y espiritual, permite comprender el proceso adelantado en las comunidades del valle del Patía, orientado a refinar conceptual y pedagógicamente los elementos que les 
iba a permitir activar su memoria colectiva, es decir, navegar por los surcos de sus pensamientos, conocimientos y experiencias mar adentro, para recuperar el sentido y el valor de un mundo históricamente visibilizado negativamente, sin ser conocido: el mundo sagrado y espiritual de los negros y negras. El trabajo de la memoria permitiría el reencuentro con el cimanorrear de los negros y negras; es decir, con aquella actitud críticamente reflexiva y con sus prácticas disruptivas, orientadas a la preservación de su condición de negros, el cuestionamiento del orden social existente, y la proyección de otro orden. Postura que configuraría la existencia de los patianos y patianas, e imprimiría a las generaciones venideras, el cimarronear como espíritu subversivo que impulsa y anima sus prácticas sociales y culturales. La memoria colectiva será entonces un factor que haría del cimarronaje, en el ámbito religioso, una potencia espiritual.

Estos planteamientos cobran sentido cuando se indaga por el principio orientador del movimiento de recuperación de tradiciones culturales en estas comunidades, en tanto el proceso de creación de las representaciones colectivas a partir de los trabajos de la memoria (celebración y rememoración) se inicia con la recuperación de las prácticas musicales y, de modo especial, de las prácticas religiosas. A este respecto Ana Amelia Caicedo dice:

La parte religiosa para los negros es muy importante, donde usted encuentra negros, es muy importante para el negro la religiosidad y nosotros, las Cantaoras comenzamos trabajando fue con eso, empezamos a recoger la parte fúnebre, los alabaos, las salves, los trisagios, los arrullos, los entierros para angelitos ${ }^{21}$, todo eso es la parte fúnebre que es importantísimo para nosotros (Ana Amelia Caicedo, Conversatorio: Patía, 2007).

Hecho que nos lleva a confirmar que uno de los rasgos culturales característicos que hacen posible la adhesión, reconocimiento y definición de la identidad de los patianos y patianas, lo constituye su espiritualidad y religiosidad. En efecto, la música, el baile y los cantos en las comunidades negras del valle interandino del río Patía, hacen parte integral de los ritos o ceremonias dedicadas a la vida, a la muerte, al territorio y a los santos. La configuración de lo divino y lo humano, lo mágico y lo religioso representado mediante los rituales, encuentra su mejor expresión en las prácticas musicales, las que han sido creadas y recreadas en su propia historia, en los aconteceres cotidianos e imaginarios colectivos; al mismo tiempo que constituyen elementos que revitalizan las identidades.

Lo anterior deja comprender el modo particular cómo los cantos fúnebres han permitido que la creencia, la fe y la devoción en lo sagrado, se transformen en palabras para ser narradas, musicalizadas y traducidas mediante símbolos en los ritos espirituales y religiosos. Los cantos fúnebres representan expresiones de carácter mágico-religioso, cuyos elementos simbólicos permiten activar y actualizar valores en los cultos, así como también comprender y determinar la importancia de los rituales o ceremonias en el contexto de estas comunidades.

Sin embargo, con el transcurrir del tiempo dichas narrativas cantaoradas $^{22}$, en tanto componentes fundamentales de los rituales en sus diferentes manifestaciones, al igual que cantaoras, rezanderos o rezanderas ${ }^{23}$, cada vez es mucho más notoria su ausencia. En esta situación, ha incidido el fallecimiento de estos últimos sin haber dejado su legado en las generaciones venideras, de forma tal que pudieran garantizar la preservación de dichas prácticas. De igual modo, y no menos importante, lo constituye la diversificación del campo religioso en la región, así como también la presencia y proliferación en las comunidades de servicios funerarios prestados por empresas para tal fin y sus cementerios. Si bien no se puede considerar estas últimas condiciones como menos religiosas, es indudable que se trata de prácticas religiosas distintas como distantes de las tradiciones ancestrales, cuya incidencia es relevante en términos de la afectación que genera en la cohesión social y la reproducción de los imaginarios que otorgan sentido a las comunidades.

La pregunta que surgía entonces era: ¿Los patianos y patianas estarían dispuestos a aceptar que sus rituales y cantos fúnebres fueran borrados de sus memorias y, por tanto, ya no formaran parte de su conciencia colectiva? La mejor manera de responder a esta pregunta son los resultados del proceso de investigación, recuperación y revitalización de las tradiciones culturales en la región, llevado a cabo por estas comunidades por más de dos décadas. Y una demostración de ello lo constituye el trabajo adelantado con los cantos fúnebres. Trabajo que ha permitido recuperar alabaos, arrullos, salves y saetas, con el principal propósito de que la comunidad 
conozca, se reconozca, implemente y difunda los cantos rituales ${ }^{24}$ como expresiones que recogen el sentir de la cultura afropatiana, cuyas interpretaciones salen desde lo más profundo de los corazones de las cantaoras (cantan y oran) del valle interandino del Patía. Podría decirse que lo que expresan los patianos y patianas por medio de su proceso de recuperación de los cantos fúnebres -para decirlo desde el punto de vista de José Jorge de Carvalho-es un enfrentamiento del poder de la comunidad sobre la música y sobre sus producciones simbólicas, pues

Por un lado está el intento de la comunidad por ejercer su poder de control sobre su música sagrada; y por otro lado está también el poder de esa música sagrada sobre la comunidad que la preserva. Porque, en la medida en que se trata de un grandioso legado de sus ancestros, hay que conservarlo. Allí se manifestaría, entonces, el poder de la música misma sobre la comunidad en que es practicada (Carvalho, 2003: 3-4).

Este planteamiento remite a considerar que la música sagrada en su manifestación fúnebre (alabaos, salves, saetas y arrullos de angelitos) es asumida por los patianos y patianas como un escenario donde se disputa simbólicamente por el control de los significados. En otras palabras, se lucha por aquello que le imprime una contundente carga semántica a las ideas, sentimientos, valores y prácticas religiosas en estas comunidades, lo que cobra sentido en términos de sus identidades religiosas y culturales. Lo anterior, nos lleva a plantear que el mundo religioso afropatiano no es un estado puro de ideas; contrario a ello, es humano, realidad social y cultural que se vive y sitúa en un espacio, en un tiempo y en un contexto social determinados. Pero con la particular característica de estar en permanente relación/tensión con lo sagrado hegemónico, dominante y oficial, al punto que, en el mayor de los casos y circunstancias, su dinámica lo sitúa en los ámbitos de la transgresión, el desajuste e, inclusive, de su definitiva disolución.

\section{Conclusiones}

De acuerdo con todo lo expuesto, se podrían establecer, a modo de conclusiones, los siguientes horizontes de reflexión y discusión:
Primero, la persistencia del creer en comunidades locales como las del valle geográfico del Patía, se sitúa al nivel del reencuentro con las creencias, tradiciones y prácticas ancestrales, resultante de procesos de recuperación y revitalización de las mismas, por medio de la oralidad y la activación de las memorias. Situación que las diferencia y hasta cierto punto, las distancia, de una parte, del permanente proceso de cambio de adscripción religiosa, también conocido como "conversiones", propias de los sujetos en los ya mencionados contextos plurales religiosos contemporáneos y, por otra parte, de prácticas religiosas, como expresiones de cuerpos de doctrina sustentados en textos sagrados, organizadas bajo la forma de Iglesia de donde derivan preceptos sacramentales, rituales y morales, cuya teología examina y ofrece legitimidad a las creencias y lo sagrado.

Segundo, las expresiones de religiosidad y espiritualidad en las comunidades que nos ocupan, no constituyen un corpus discursivo y práctico que las inscriba e identifique colectivamente como una religión, pues se caracterizan por actitudes de trascendencia, al asumir el mundo religioso en el plano de otra dimensión existencial mucho más rica y sentida para el devoto, como resultado del proceso continuo de interpelación y resistencia al proyecto de cultura religiosa, política, económica y social de mirada colonial.

Tercero, la forma cómo estas comunidades encaran lo sagrado, escapa a los dualismos monoculturales prescritos por Occidente y, en consecuencia, asume y disputa por hacer manifiesta dicha realidad, desde otro patrón epistémico, sociocultural y religioso. Por tanto, hace posible reconocer la existencia de lo "sagrado", por fuera del marco interpretativo de las organizaciones o colectividades, estrictamente definido como "religiosas". Lo anterior le confiere legitimidad a demandar la discusión en torno al cimarronaje religioso como estrategia propia de reexistencia identitaria, sociocultural y política; es decir, "una concepción que va a suponer una lucha $\mathrm{y}$ un desplazamiento hacia un campo religioso y de expresión ritual, desde el cual la realidad y sus universos simbólicos, no quedan sometidos al yugo de la estructura, la lógica y las representaciones del sistema religioso etnocéntrico oficial" (Rosero 2015).

Cuarto, la religiosidad y espiritualidad en determinados contextos y circunscritas, puede llegar a adquirir un sentido potenciador y crítico. En referencia a este planteamiento, múltiples estudios ${ }^{25}$ realizados durante las tres últimas décadas en América Latina, 
y particularmente en México y Mesoamérica, vienen demostrando la inmensa capacidad que poseen las religiones para expresar, agenciar e impulsar, de una parte, las demandas de las minorías étnicas y culturales y de amplios sectores inconformes de la sociedad y, por otra parte, sus gestas y procesos de lucha. Expresiones que en muchos casos se han traducido en la conformación de organizaciones y movimientos sociorreligiosos y políticos que activan procesos de rebeldía, disidencia y resistencia.

$\mathrm{Y}$, en quinto lugar, ante la pregunta ¿dónde situar las expresiones religiosas y espirituales de las poblaciones negras del valle interandino del río Patía $\mathrm{y}$, en consecuencia, bajo qué formas comprenderlas en nuestro contexto?, podría considerarse que la noción de religiosidad y espiritualidad marginal o disruptiva, resulta ser una unidad de análisis pertinente y potencialmente esclarecedora para la comprensión de las relaciones que establecen las comunidades con lo sagrado, y a la que -valga decirlo-hemos llegado por vía de la experiencia de esta investigación, en el contexto sociocultural que particulariza a estas comunidades locales.

\section{Referencias Citadas}

Abrámova, Marianna

2020 "Neopentecostales en América Latina: ¿Declive de la política pública o nuevos actores políticos del siglo XXI?". Iberoamérica, $\mathrm{N}^{\circ}$ 1, pp. 90-108. https://iberoamericajournal. ru/sites/default/files/2020/1/abramova_2.pdf

Aguirre, Federico

2020 "Tradición y transmisión de la fe. El caso de la "religiosidad popular" en el Chile actual". Scripta Theologica. Vol. 52, No 1, pp.215-243. Universidad de Navarra.

Alves, Sintya y Rocío Pérez

2016 "Miradas divinas: elementos de resistencia a la colonización de la península ibérica en las expresiones religiosas afroecuatoriana y afrobrasileña”. Revista Diálogo Andino No 49. pp. 81-89. https://scielo.conicyt.cl/pdf/rda/n49/art10. pdf

Ameigeiras, Aldo

2008 Religiosidad popular: creencias religiosas populares en la sociedad argentina. $1^{\circ}$ Edición. Editorial Los Polvorines: Universidad Nacional de General Sarmiento, Buenos Aires: Biblioteca Nacional.

Ameigeiras, Aldo y Martín, José (Eds)

2008 Religión, Política y Sociedad. Pujas y transformaciones en la historia argentina reciente. Prometeo Libros-Universidad nacional General Sarmiento: Buenos Aires.

Arboleda, Carlos

2005 "Tendencias de la Religión hacia el Futuro". En: Globalización y Diversidad Religiosa en Colombia (Ana María Bidegaín, Juan Diego Demera, Comp.). Universidad Nacional de Colombia. Colección Sede: Bogotá.

Barabas, Alicia

1986 Utopías indias. Movimientos socioreligiosos en México. México: Ediciones Era.

Barabas, Alicia

2002 "Etnoterritorios y rituales terapéuticos en Oaxaca" En: Scripta Ethnológica (Argentina), Num.024. pp. 9-19. Conicet: Buenos Aires.

Barabas, Alicia

2008 "Cosmovisiones y etnoterritorialidad en las culturas indígenas Oaxaca". En: Antípoda $\mathrm{N}^{\mathrm{o}} 7$ [julio-diciembre], pp. 119-139. Universidad de Los Andes: Bogotá.

Barabas, Alicia \& Bartolomé, Miguel

2010 Dinámicas culturales. Religiones y migración en Oaxaca. México: Secretaría de Cultura Gobierno del estado de Oaxaca.
Bartolomé, Miguel

1997 "Gente de costumbre y gente de razón. Las identidades étnicas en México”. INI/Siglo Veintiuno Editores. México.

Bastián, Jean-Pierre

2003 La Mutación Religiosa de América Latina. Para una sociología del cambio social en la modernidad periférica. Fondo de Cultura Económica: México.

Bastián, Jean-Pierre

1994 Protestantismos y modernidad latinoamericana: historia de unas minorías religiosas activas en América Latina. Fondo de Cultura Económica. México.

Bastián, Jean-Pierre (Coord.,)

2004 La modernidad religiosa: Europa latina y América Latina en perspectiva comparada. Fondo de Cultura Económica: México.

Beltrán, William

2012 "Descripción cuantitativa de la pluralización religiosa en Colombia". En: Universitas humanística No.73 [enerojunio]. Universidad Javeriana: Bogotá. pp. 201-237.

Bidegaín, Ana

2004 (Dir). Historia del cristianismo en Colombia. Corrientes y Diversidad. Taurus: Bogotá.

Bidegaín, Ana y Demera, Juan (Comps.)

2005 Globalización y Diversidad Religiosa en Colombia. Universidad Nacional de Colombia: Bogotá.

Brower, Jorge

2007 "Aproximación preliminar al pensamiento heterológico". Estudios Avanzados (2007) 5(8): 113-127.

Capiche, Roland

2004 "El nuevo despliegue de la religión en un contexto pluralista". En: Bastián, Jean-Pierre (Coord.,). La modernidad religiosa: Europa latina y América Latina en perspectiva comparada. Fondo de Cultura Económica: México.

Carvalho, José

2003 "La Etnomusicología en Tiempos de Canibalismo Musical. Una Reflexión a partir de las Tradiciones Musicales Afroamericanas". Série Antropología 335. Departamento de Antropología. Instituto de Ciências Sociais. Universidade de Brasília: Brasília.

Cerutti, Horacio

2011 Doscientos años de pensamiento filosófico Nuestroamericano. Ediciones Desde Abajo: Bogotá. 
Delgado, Manuel

1993 "La "religiosidad popular". En torno a un falso proble-

ma”. En: Gazeta Antropológica, No 10: Granada, España.

Durkheim, Emile

1982 Las formas elementales de la vida religiosa. Akal. Madrid.

Eliade, Mircea

1998 Lo Sagrado y lo Profano. Ediciones Paidós: Barcelona.

Fanon, Frantz

2001 Los condenados de la tierra. Fondo de Cultura Económica: México.

Fornet, Raúl

2007 Interculturalidad y Religión. Ediciones Abya-Yala-

Agenda Latinoamericana: Quito, Ecuador.

Freire, Paulo

2002 Pedagogía del Oprimido. Siglo XXI Editores: Argentina.

Gómez, Ramiro

2007 "Una Visión Antropológica de la llamada 'Religiosidad

Popular"'. En: Revista Intersticios, Año 12, № 26. Escuela de

Filosofía del Instituto Internacional de Filosofía, Universidad

Intercontinental: México.

Gómez-Quintero, Juan

2010 "La colonialidad del ser y del saber: la mitologización del desarrollo en América Latina". En: Revista El Ágora USB. V. $10 \mathrm{~N}$ 1. [enero-junio]. Medellín-Colombia ps. 87-105.

Gooren, Henri

2018 "Pentecostalization and Politics in Paraguay and Chile". Religions 9-340. www.mdpi.com/journal/religions

Gudemos, Mónica y Francisco Gil.

2012 "Espacios ceremoniales andinos. De tradiciones, creencias y coexistencias". Revista Diálogo Andino No 39 . pp. 5-8. http://dialogoandino.cl/wp-content/uploads/2016/07/ DA-39-2012-01.pdf

Herrera, Nicolás y Lorena López (Comps.)

2014 Ciencia, compromiso y cambio social. Orlando Fals Borda, Antología. Extensión Libros. Colección Pensamiento Latinoamericano: Montevideo.

Hervieu-Léger, Daniéle

1987 "Secularización y modernidad religiosa". En: Selecciones de Teología. Vol. $26 \mathrm{~N}^{\circ} 103$.

Hervieu-Léger, Daniéle

2005 La Religión, hilo de la memoria. Barcelona: Herder.

Kusch, Rodolfo

1973 Pensamiento Indígena y Popular en América. ICA: Buenos Aires.

Lecaros, Véronique

2020 "L'existence de Dieu, une évidence en Amérique Latine". Theologica Xaveriana, Vol. 70. pp. 1-27. https:// doi.org/10.11144/javeriana.tx70.1deal

Lecaros, Véronique

2017 "Estudios de recorridos religiosos: los desafiliados en contexto". Estudos de Religão, Vol. 31, No 3. pp. 71-90.

Lindhardt, Martin

2020 "Pushing Pentecostalism toward the respectable: on the mainstreaming of a countercultural religious movement in

Chile". Religion. https://www.tandfonline.com/doi/abs/10 .1080/0048721X.2020.1712054

Losada, Jhon

2014 Ontología y Poder Colonial. Claves analíticas a propósito de la colonialidad del ser. Editorial Universidad de San Buenaventura. Bogotá.
Maldonado-Torres, Nelson

2007 "Sobre la colonialidad del ser: contribuciones al desarrollo de un concepto". En: Castro-Gómez, S. y Grosfoguel, R. (eds.): El giro decolonial. Reflexiones para una diversidad epistémica más allá del capitalismo global. Bogotá, IescoPensar-Siglo del Hombre Editores, pp.127-167.

Mallimaci, Fortunato

1993 "Religión, modernidad y catolicismo integral en Argentina”. En. Perfiles Latinoamericanos, $\mathrm{N}^{\mathrm{o}} 2$, [junio]. Facultad Latinoamericana de Ciencias Sociales: México. pp. 105-131. Recuperado de: http://www.redalyc.org/articulo. oa?id=11500205

Mardones, José

1999a "Raíces sociales del ateísmo moderno". En: Ateísmo moderno: increencia o indiferencia religiosa. José Gómez Caffarena y José María Mardones. (Fe-Cultura No 8). Centro de Integración Universitaria. Universidad Iberoaméricana: México

Mardones, José

1999b Síntomas de un retorno. La religión en el pensamiento actual. Editorial Sal Terrae: Santander, España.

Martínez, Sarelly et al.

2013 "El Púlpito Electrónico: La Radio Religiosa en Chiapas". En: Razón y Palabra. Primera Revista Electrónica en América Latina Especializada en Comunicación. Centro Avanzado de Comunicación - 25 Aniversario Eulalio Ferrer Número 83 Junio-Agosto. Recuperado de: www.razonypalabra.org. $\mathrm{mx}$.

Marzal, Manuel

2002 Tierra Encantada. Tratado de Antropología Religiosa de América Latina. Editorial Trotta: Madrid.

Mignolo, Walter

2003 "Pensamiento fronterizo y diferencia colonial" En: Historias locales-diseños globales: colonialidad, conocimientos subalternos y pensamiento fronterizo. Akal: Madrid. pp. 111-153.

Minda, Pablo

1996 "El Negro en Sucumbíos. Migración, Cultura e Identidad." En: Identidades en Construcción. Colección de Antropología Aplicada No 10. Ediciones Abya Yala: Quito.

Mondragón, Carlos

2006 "Utopía y Religión en América Latina: la subversión de la esperanza”. En: Horacio Cerruti G y Carlos Mondragón G (Coord.) Religión y Política en América Latina: la utopía como espacio de resistencia social. México: Centro Coordinador y difusor de estudios latinoamericanos, UNAM.

Otto, Rudolf.

1996 Lo Santo. Lo racional y lo irracional en la idea de Dios. Alianza Editorial: Madrid.

Olivera, Mercedes

2011 "Cosmovisión maya y género en Chiapas y Guatemala". Centro de Estudios Superiores de México y Centroamérica. Centro de Derechos de la Mujer en Chiapas.

Panikkar, Raimon

1999 La intuición cosmoteándrica, Editorial Trotta: Madrid.

Panikkar, Raimon

1991 "La visió cosmoteàndrica: el sentit religiós emergent del tercer mil.leni”. En: Qüestions de Vida Cristiana, $\mathrm{N}^{\circ} 156$. pp. 78-102. [La visión cosmoteandrica: el sentido religioso emergente del tercer milenio]. Tradujo y condensó: Javier Melloni. Recuperado de: http://www.seleccionesdeteologia. net/selecciones/llib/vol32/125/125_panikkar.pdf 
Parker, Cristian

1996 Otra Lógica en América latina. Religión Popular y Modernización Capitalista. Fondo de Cultura Económica: Chile.

Parker, Cristian

2005 “AAmérica Latina ya no es católica? Pluralismo cultural y religioso creciente". En: Revista América Latina Hoy, pp. 35-56. Recuperado de: http://www.redalyc.org/articulo. oa? id=30804102

Parker, Cristian

1995 "La Sociología de la Religión y la Modernidad: Por una revisión crítica de las categorías durkhenianas desde América Latina". En: Sociedad y Religión $\mathrm{N}^{\circ} 13$. Sociedad, antropología e historia de la religión en el Cono Sur. Argentina.

Rabasa, José

2010 "Espiritualidades revolucionarias en Chiapas: Historia inmanente y marco comparativo en los estudios subalternos". En: Cuadernos de Literatura 14. 28 Bogotá [julio-diciembre], pp. 260-287.

Rappaport, Joanne

2015 "Letramiento y mestizaje en el nuevo Reino de Granada, siglos XVI y XVII". Revista Diálogo Andino No 46. pp. 9-26. https://scielo.conicyt.cl/pdf/rda/n46/art02.pdf

Roldán, V

1999 "La secularización y el despertar religioso a fin del milenio”. En: Revista CIAS, XLVIII, N 484.pp. 273-292.

Rosero, José

2008 "Patía: religiosidad y resistencia o de cómo un pueblo revitaliza la cultura y la identidad. Una ruta exploratoria de investigación". En: Revista de Estudios Sociales Comparativos, Vol. 2. $\mathrm{N}^{\circ}$ 2. Universidad del Cauca, Colombia. pp. 38-76.
Rosero, José

2015 "Éthos Cimarrón, Cimarronaje Religioso e Identidades en el Valle Geográfico del Patía-Colombia”. En: Revista Opción, Año 31, No. 78. pp. 110-137.

Serna, Jesús

2006 "Religiosidad popular en los procesos de construcción de nuevas utopías en algunas comunidades Chiapanecas". En: Horacio Cerruti G y Carlos Mondragón G (Coord.,) Religión y Política en América Latina: la utopía como espacio de resistencia social. México: Centro Coordinador y difusor de estudios latinoamericanos, UNAM.

Serrano, José

1998 "'Hemo de mori cantando, porque llorando nací". Ritos Fúnebres como forma de cimarronaje”. En: Adriana Maya (ed.), Los Afrocolombianos. Geografía Humana de Colombia. Tomo VI. Instituto Colombiano de Cultura Hispánica: Bogotá. pp. 241-262.

Torres, Alfonso

2008 "Investigar en los márgenes de las ciencias sociales". En: Revista Folios $\mathrm{N}^{\circ} 27$ [junio]. Facultad de Humanidades de la Universidad Pedagógica Nacional: Bogotá. pp. 51-62.

Zamora, Elías

1989 “Aproximación a la Religiosidad Popular en el Mundo Urbano: El Culto a los santos en la ciudad de Sevilla”. En: La Religiosidad Popular. Compilación Álvarez Santalo, C y Otros. Barcelona: Barcelona.

Zuluaga, Francisco

2006 "El paraguas. Las formas de hacer historia local." En: Historia y Espacio. Revista N ${ }^{\circ}$ 26, Departamento de Historia, Universidad del Valle: Santiago de Cali, Colombia.

Notas

1 Conviene precisar que "América Latina ha dejado de ser 'católica' en el sentido tradicional del término. Las alternativas al catolicismo no han provenido (salvo las excepciones históricas de Cuba y Uruguay) del crecimiento de la no creencia y mucho menos del ateísmo. Por otra parte, América Latina es más 'evangélica' solo en forma relativa" (Parker 2005:36).

2 La investigadora Ana María Bidegaín Greising ofrece una excelente caracterización del escenario religioso plural contemporáneo. En este sentido, plantea que este escenario se distingue por la creciente diversificación religiosa (movimientos adventistas y milenaristas, evangélicos y pentecostalismos, entre otros); la notoria tendencia hacia la desinstitucionalización y afirmación de experiencias religiosas individualizadas; el redimensionamiento de la experiencia pública de lo religioso; los liderazgos religiosos de las mujeres, y la revitalización de expresiones religiosas amerindias y afrodescendientes (Cfr. Bidegain 2005:Introducción; véase también Bidegaín 2004).

3 Entendemos aquí lo marginal, siguiendo a Alfonso Torres Carrillo (2008:54), como el no estar por fuera, sino en el umbral, en las fronteras: entre el adentro y el afuera, entre lo instituido y lo instituyente, entre lo conocido y lo inédito, entre lo determinado y lo indeterminado. Así, lo marginal abre nuevas posibilidades para pensar, para imaginar, para construir nueva realidad.
$4 \quad$ Respecto del tema, Francisco Zuluaga (2006:14) argumenta que " $[. .$.$] lo local no está fuera de nosotros, fuera de una$ (nuestra) cultura, lo local está en nosotros siendo nosotros con y entre los otros, con los demás, sabiéndonos un caso entre otros casos y un mundo entre otros mundos. De esta manera se libera lo local (la localidad) del imperativo de definirse necesariamente por el espacio físico y se abren nuevas posibilidades".

5 Esta expresión alude a visiones de mundo, en nuestro caso religiosas, que logran conjugar creencia, sentimiento, corazón y pensamiento. Expresión que es tomada aquí, de esa bella y antigua metáfora que Orlando Fals Borda usara para dar cuenta de la condición doblemente intelectual de quienes como dicen los indígenas nasa, piensan con el corazón, o encarnan el ethos cimarrón de los afrocolombianos, para significar la increíble capacidad de sentirse en el pensar. Al respecto, véase el trabajo de Herrera y López (2012).

6 Recomposición religiosa es una expresión y un tema que a partir de la década de los ochenta se ha tornado recurrente, particularmente en el ámbito de la sociología de las religiones, el que "permite comprender la secularización no en términos de pérdida, sino de cambio, incluso de transformación religiosa". (Cfr. Capiche 2004).

7 Acerca del paradigma de la secularización y sus implicaciones asociadas a los cambios de adscripción religiosa: afiliaciones, conversiones y desafiliaciones y, la relación/ 
tensión entre creencias religiosas y contenidos de las creencias religiosas en el contexto latinoamericano, ver: Lecaros 2017, 2020.

8 Bajo el término "creer" se designa el conjunto de convicciones, individuales y colectivas, que si bien no se desprenden de la verificación y la experimentación, ni, de manera más amplia, de los modos de reconocimiento y control que caracterizan el saber, encuentran sin embargo su razón de ser en el hecho de que dan sentido y coherencia a la experiencia subjetiva de quienes la mantienen (HervieuLéger 2005: 122).

9 Conviene señalar aquí que dentro de las visiones alternativas de lo religioso, cobra valor e importancia en el contexto latinoamericano, la presencia de los pentecostalismos y neopentecostalismos, pues además de producir redefiniciones de su religión, reconocimiento público cada vez mayor, y revisiones respecto de sus discursos y prácticas, vienen adquiriendo un destacado papel en términos de su agencia y participación política, al convertirse en expresión de la inconformidad de sus comunidades y vehículo de las aspiraciones morales de la población (Cfr. Abrámova 2020, Lindhardt 2020, Gooren 2018).

10 Un significativo estudio que -pertinente a cifras confiablespermite dimensionar, observar y proyectar las tendencias de la pluralización religiosa en Colombia, es el adelantado por William Mauricio Beltrán (2012).

11 Acojo aquí las elaboraciones y el concepto de pensamiento heterológico acuñado por Jorge Brower Beltramin en: "Aproximación preliminar al pensamiento heterológico". Estudios Avanzados (2007) 5(8): 113-127.

12 En términos de Kusch, "pensar en clave andino", supone que la función de las cosas y las acciones no siempre se definen a partir de un destino inmediato, único, práctico o técnico, toda vez que ello implica una compleja condensación significativa y simbólica (Cfr. Gudemos y Gil 2012: 7).

13 A este respecto, Horacio Cerutti Guldberg ha señalado que "Las civilizaciones del libro, no por casualidad correspondientes a las tres religiones monoteístas (judaísmo, cristianismo, islamismo), han impulsado su expansión por el globo mediante usos violentos sin piedad ninguna. [...] La historia de la expansión del cristianismo está plagada de destrucción, aniquilación, imposición" (Cerutti 2011:10).

14 Catolicismo: del griego $\kappa \alpha \theta 0 \lambda \iota \kappa o ́ \varsigma$, katholikós y del latín, Catholicus, término cuyo significado es "universal", el que en sí mismo está referido a lo que afecta al mundo entero y a toda la gente en él. En otras palabras, que lo abarca todo, en tanto dispone de todos los medios necesarios para lograr la salvación del mundo, en todos los tiempos y lugares.

15 En otro lugar he planteado que es posible pensar un cimarronaje religioso en el contexto de comunidades negras como las del valle interandino del río Patía (Cauca). Lo anterior, sobre la base de que un ethos cimarrón habría permitido que la religiosidad y espiritualidad fuese asumida como la manifestación de una lógica cultural coherente con el proceso social históricamente vivido, con todas las tensiones, rupturas y adopciones que ello conlleva, pero sin dejar que lo religioso hegemónicamente institucionalizado, la invada en su totalidad (Rosero 2015).

16 Para un desarrollo contextualizado acerca del concepto de colonialidad del ser, véase: Losada Cubillos, J. 2014.
Ontología y Poder Colonial. Claves analíticas a propósito de la colonialidad del ser. Cuestionamientos. Bogotá: Editorial Universidad de San Buenaventura. GómezQuintero, Juan David. 2010. "La colonialidad del ser y del saber: la mitologización del desarrollo en América Latina". En: Revista El Ágora USB. V. 10 N 1. [Enerojunio]. Medellín-Colombia ps. 87-105.

17 Maldonado-Torres recurre a Fanon con el fin de aclarar la experiencia vivida del negro y del colonizado. Así como también para retomar el concepto de damné [condenado] como elemento fundamental en el desarrollo de su concepto de colonialidad del ser; es decir, como un no ser o, más concretamente, un ser que no está ahí. Esta referencia remite a Los condenados de la tierra (Fanon 2001).

18 La oposición sagrado/profano es sin duda desde su emergencia a comienzos de siglo XX en Europa uno de los horizontes de análisis de mayor aceptación y difusión. Este se sustenta inicialmente desde una perspectiva socioantropológica, en la rígida separación durkheimiana (1982) entre sagrado/ profano. Perspectiva que principalmente va a ser objeto de continuidad y desarrollo por Rudolf Otto(1996) desde el enfoque de la psicología, y por Mircea Eliade (1998) desde la fenomenología del hecho religioso en articulación con la historia.

19 Cristian Parker plantea que "No es nada extraño que Durkheim mirara con cierto prejuicio a las expresiones religioso-populares de su época: 'Son en general retazos de religiones desaparecidas, sobrevivencia desorganizadas; pero hay también aquellas que son formadas espontáneamente bajo la influencia de causas locales"'. Y agrega: "Como vemos una vez más la fuerza creadora de lo religioso es una causa impersonal y no un sujeto social. ¿Dónde está el sujeto que crea o recrea la fe popular en Durkheim? No existe" (Parker 1995: 140. Nota al pie de página).

20 Según Panikkar (1991), "la división triádica de la realidad (lo divino, lo humano y lo cósmico) es una constante de la cultura humana que encontramos por doquier: tanto en términos espaciales (cielo, tierra, ultratumba), como en los temporales (pasado, presente, futuro), e incluso en los cosmológicos o metafísicos (cuerpo, alma, espíritu)".

21 Entre las comunidades negras del valle geográfico del Patía se denomina "entierro o velorio de angelito", al ritual fúnebre con ocasión de la muerte de un niño o niña menor de 7 u 8 años. Este ritual se realiza en un día y no requiere de novenario. En él se baila, se juega y se interpretan arrullos. En comunidades negras del Pacífico también es conocido este ritual como "Chigualo" o "Gualí".

22 Se entiende aquí por narrativas cantaoradas, aquellos relatos o enunciaciones que pueden ser musicalizados, cantados, entonados o pronunciados oralmente en las comunidades, para expresar creencias, sentimientos, emociones e identidades por medio de los rituales.

23 En el contexto de las comunidades afrocolombianas, los rezanderos o rezanderas son personas mayores de la comunidad, las que se encargan de entonar los rosarios, oraciones, novenas a los santos y letanías para el alivio y descanso del alma de los difuntos. De igual modo, tienen por oficio dirigir la partida del espíritu finado que permanece sobre el altar funerario durante todo el novenario y el que parte al infinito al "levantar la tumba". Esta función, según la tradición, es la que ayudará al difunto a descansar en paz. 
La expresión "levantar tumba" está referida a una práctica utilizada para despedir de forma definitiva el alma del difunto el último día del novenario. Ese día se construye un altar nuevo o se arregla el que se ha usado los días anteriores para sellar la partida del difunto. Mientras se levanta la tumba y se retiran los atuendos, se cantan todo el tiempo versos. La tumba se levanta antes de que salga el sol del nuevo día.

24 En el marco del proyecto investigación "Rituales para la Memoria”, desarrollado por el Grupo de Investigación Cultura y Política de la Universidad del Cauca y financiado por la Vicerrectoría de Investigaciones de la misma universidad, se contribuyó con la grabación de dos Discos Compactos
(CDs). El primero, lleva por título "Cantos Fúnebres en el Valle del Patía", el que recoge alabaos, arrullos, salves y saetas interpretados por el "Grupo de Cantaoras del Patía". El segundo, titulado "Navidad en el Tuno. Villancicos y arrullos al Niño Dios", el que recoge villancicos y arrullos interpretados por el "Grupo Alegría y Fe" de la vereda El Tuno (Patía, Colombia).

25 Véase, por ejemplo, los estudios de Serna (2006), Barabas (1986, 2002, 2008, 2010); Bartolomé (1997, 2010); Rivera Farfán et al. (2005); Bastián (1994,2003); Rabasa (2010); Olivera (2011); Mondragón (2006); Martínez Mendoza et al., (2013), entre otros. 